\title{
The Structure Design and Mixing Principle Study of a New Device of Fluid Mixing
}

\author{
Luo Qiancheng \\ School of Petroleum Engineering \\ Chongqing University of Science \& Technology, \\ Chongqing, China \\ 1213847589@qq.com
}

\author{
Jiang Yurong* \\ School of Petroleum Engineering \\ Chongqing University of Science \& Technology, \\ Chongqing, China \\ *381012115@qq.com(Corresponding author)
}

\author{
Zhu Pengyang \\ School of Petroleum Engineering \\ Chongqing University of Science \& Technology, \\ Chongqing, China \\ 857001385@qq.com \\ Li Xintong \\ School of Petroleum Engineering \\ Chongqing University of Science \& Technology, \\ Chongqing, China \\ 275417388@qq.com
}

\begin{abstract}
In order to overcome the shortcomings of the traditional mixing device, a new type of multi-purpose fluid mixing device is developed which has the reasonable design of mixing chamber, baffle and flow structure through the principle of fluid mechanics. The new multi-purpose fluid mixing device can mix two or three kinds of fluid quickly. The device is composed by the fluid jet entrance section, main mixing chamber and export hybrid tube. The fluidic element and the symmetric structure of baffle increase the mixing efficiency and the experimental results showed that the new device of fluid mixing has a good efficiency on mixing. It is characterized by flash fluid mix, adjustable fluid density, easy-to-use, small size and easy maintenance.
\end{abstract}

Keywords- fluid mixing device, structure design, mixing principle, flow channel, baffle

\section{INTRODUCTION}

In the process flow of petroleum, chemical, pharmaceutical, beverage, brewing and other industries, it is needed to mix a few (2 or 3 ) kinds of liquids in a certain ratio in order to adjust the density or deal with them accordingly [1-3]. Two methods are commonly used today [4-6]: one is artificial, pumping two liquids into the storage container according to the mixing ratio intermittently and quantificational to stir to mix. The other method is using the computers to pump the two liquids continuously into the storage container with the flow detection device respectively detecting the flow of both liquids, and then transforming them into electrical signals transmitting to the computer which will calculate the ratio of the two to compare with the required mixing ratio.

The first method has the advantage of easy to control and accurate, but cannot make continuously-mixing production, thus often used in the production of a small quantity of substance[7,8]. The second one could be controlled precisely and make continuous production, but the process is relatively complicated, and the devices cost much at the same time[9-11]. Besides, both methods need a storage container of large capacity and mixing devices which have large volumes and a lot of movable sections which make them fragile, so they are not suitable for rapid and stable mixing adjustment, neither are they suitable for some occasions which has limited space.

This device is designed with the principle of fluid mechanics, according to the proper design of the mixing chamber, baffle structure and flow channel and so on. A new type of multi-purpose fluid mixing device was developed. This fluid device has the advantages of high efficiency, small size, good maneuverability and larger flow which could realize the non-additional-energy mixing, and it is simple, practical, highly operable with little requirement of space and easy to maintain. This device can be widely applied in petrochemical industry, which can especially meet the requirement of the mud density adjustment of oil drilling and the space need of offshore drilling platform. It also has the ability to quickly get the proper mud density to achieve the goal of balance formation pressure[12-15].The device not only could be used for regular production, but also can be used as an emergency equipment to prevent and deal with blowout, leakage and collapse.

\section{STRUCTURE DESIGN AND MIXING PRINCIPLE}

\section{A. Structure design of the new type fluid mixing device}

The structure of the new type fluid mixing device is designed to be simple, which has the following characteristics: no moving parts, long life expectancy and easy to maintain. The structure mainly consists of the following three systems: fluid inlet jet part (1), the main mixing chamber (2) and outlet mixing tube (3), which are shown in the Fig.1. The three dimentional entities picture of the new type fluid mixing device is shown in the Fig.2. 


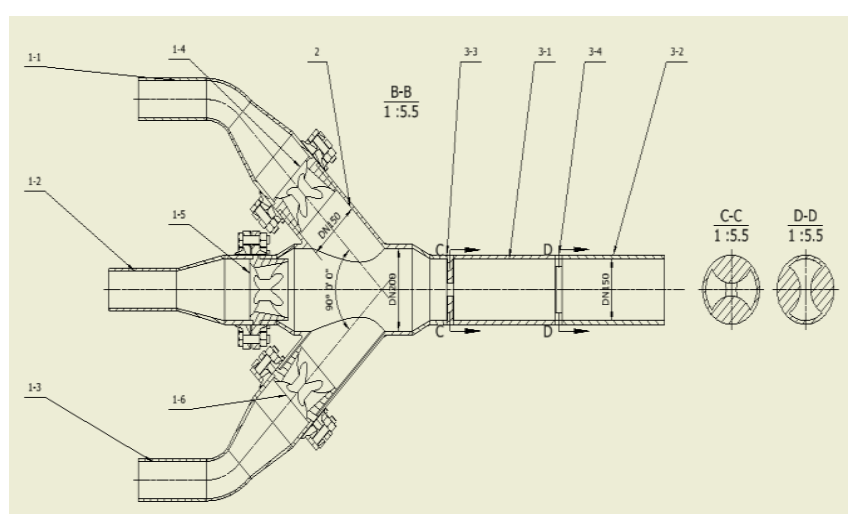

1-inlet jet pipe system, 2- main mixing chamber system, 3-outlet mixing tube system

Figure 1. structure design of the new type fluid mixing device

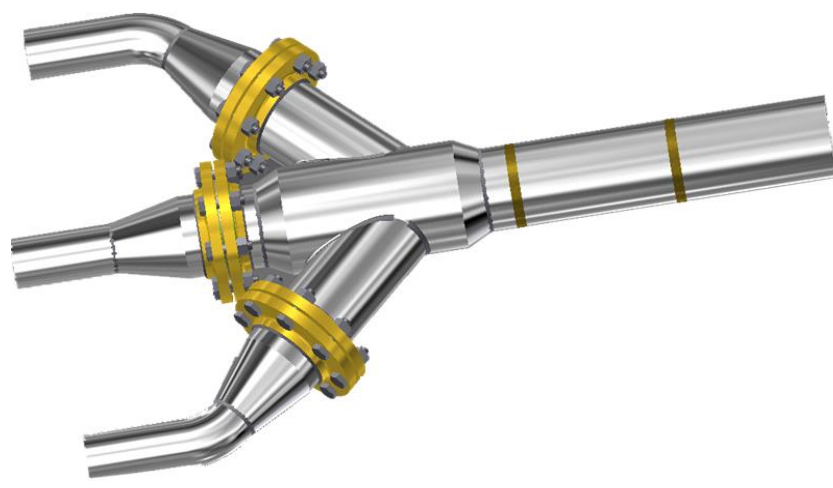

Figure 2. three dimentional entities of the new type fluid mixing device

Fluid inlet jet part system (1) includes three sections of inlet jet pipes with variable diameter from DN90 to DN150 (1-1, 1-2, 1-3). The jet components $(1-4,1-5,1-6)$ are installed in the fluid inlet jet pipes $(1-1,1-2,1-3)$ with DN150 diameter. The different fluids can be introduced into the inlet jet pipes (1-1, 1-2, 1-3). The structure design of variable diameter from DN90 to DN150 can be used to slow down the rate of fluid flowing and extend the mixing time in order to improve the efficiency of mixing. The DN150 pipes are installed with jet components (1-4, 1-5, 1-6) to control the flowing state of the fluid in order to enhance the mixing effect.

The main mixing chamber (2) is welded with a pipe segment with the Y-shaped structure, which is the first place where fluid is mixed. The main body is consisted of three sections that the diameter is DN200, which are arranged in the same horizontal plane and the angle of the pipe is $90^{\circ}$ between the sides of the tube to improve the jet mixing effect.

The outlet of the mixing pipe (3) is made of two straight pipes (3-1, 3-2) with the diameter of DN150. It is installed bezel between the two straight pipes and the main body mixing chamber $(3-3,3-4)$. The outlet of the mixing pipe (3) between the two straight pipes DN150 mixing chamber and the main body (2) are mounted at the outlet of the mixing effect of further improved baffle (3-3, 3-4), where in the direction of the shutter is $90^{\circ}$.

\section{B. Structure design of the mainly components}

1) The jet elements: The jet elements (1-4, 1-5, 1-6) are installed in the fluid inlet jet pipes $(1-1,1-2,1-3)$ with DN150 diameter. The jet elements are used to control the fluid states which can improve the efficiency and effect of mixing. The structure design of the jet element is shown in the Fig.3.

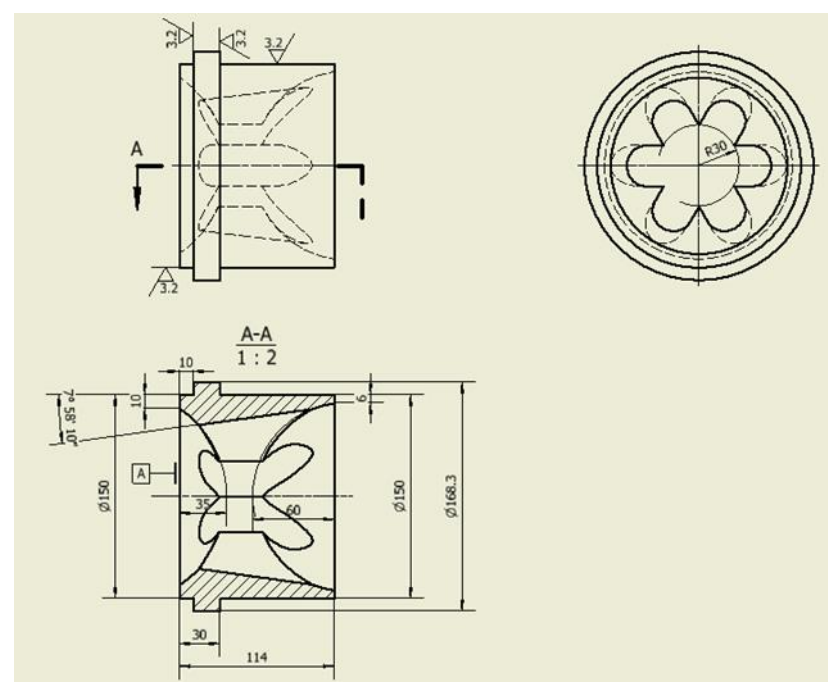

Figure 3. structure design of the jet element

Against the problem of shortening longevity of the fluidic element in complex fluid media environment, during design the structure of the jet element, one method is to make the calculation of the fluidic element' $s$ inner surface friction reasonable; the other is to comprehensively improve the inner surface hardness, wear-resisting property, cavitation resistance and partly impaction resistance of the fluidic element.

On the other hand, further research should analyses its friction mechanism upon the materials' properties of the fluidic element, and builds the mathematic module of the fluidic element scoured by the mud fluid from the macroscopic and microscopic view.

2) The main mixing chamber: The structure design of the main mixing chamber is shown in the Fig4.

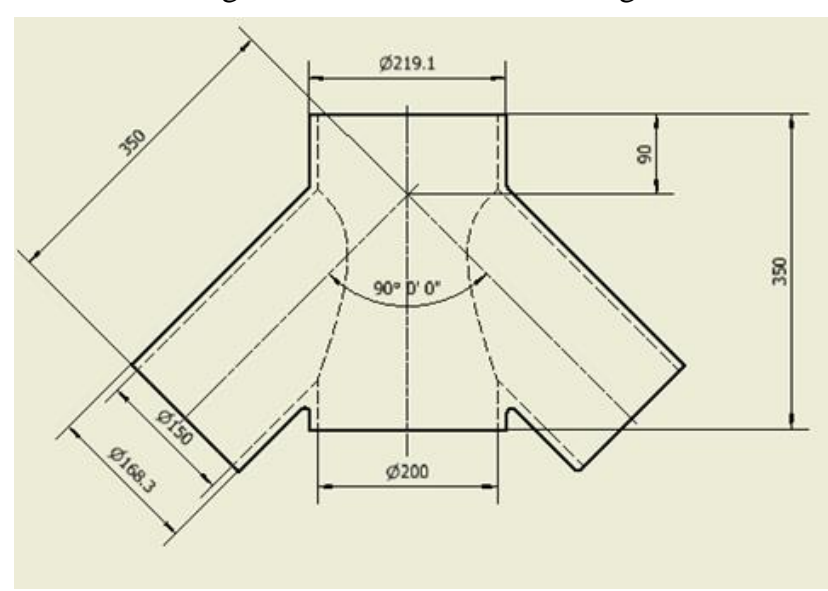

Figure 4. structure design of the main mixing chamber

3) The baffle: The structure design of the baffle is shown in the Fig5. 


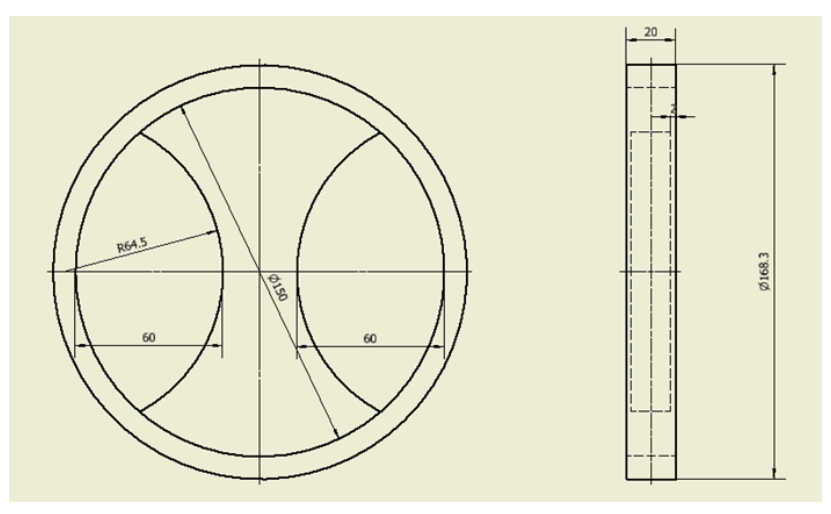

Figure 5. structure design of the baffle

\section{Mixing principle of the device}

The fluid mixing device uses fluid mechanics to improve the mixing effect through rational design of the mixing chamber, the baffle structure and the flow channel. The following four aspects can ensure the mixing effect of the fluids.

First, the diameter of the inlet jet pipe in the fluid inlet portion of the jet pipe changes from DN90 to DN150 in order to slow down the flow velocity and extend mixing time. So, the sufficient time will be afforded for intensive the fluid mixing and improving the mixing effect.

Second, the fluid inlet portions are set in the inlet jet tube in order to control the flow state of the fluid, by adjusting the angle of the jet of fluid velocity and fluid form, etc., to enhance the mixing sufficiently.

Third, the main body portion of the mixing chamber is a welded pipe with the Y-shaped structure, and the angle between the side tube axes is $90^{\circ}$. The inlet side of the jet through the jet pipe member, a fluid impact, to further improve the mixing effect of the jet.

Finally, in the outlet of the outlet pipe, two set of straight baffles are attached. The first set of baffles parallel to the main axis of the three fluid jet inlet tubes. The second set of baffles perpendicular to the main axis of the three fluid jet inlet tubes. The fluid as far as possible in the turbulent is flow regime to further improve the mixing effect.

\section{FLUID MIXING DEVICE TECHNICAL INDICATORS AND INSTALLATION}

\section{A. Main technical parameters}

With the design calculation and experimental test, the main technical indexes of the multipurpose fluid mixing device are as follows:

The biggest displacement: $4 \mathrm{~m} 3 / \mathrm{min}$

Density adjustable range: $1.00 \mathrm{~g} / \mathrm{cm} 3-2.00 \mathrm{~g} / \mathrm{cm} 3$

Design pressure: $6.4 \mathrm{MPa}$

Apply to the fluid: Drilling mud containing solid particles, and normal fluids

Structure: The size is small, which can apply in the occasions such as offshore drilling platform.

\section{B. Device installation}

The installation of the multipurpose fluid fast mixing device is shown in Fig. 6.

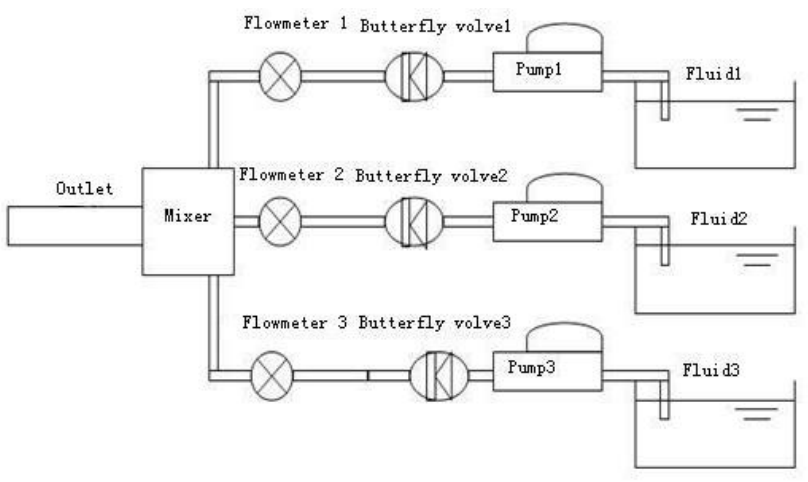

Figure 6. multipurpose fluid fast mixing adjusting device installation schematic diagram

Multipurpose fluid mixing device's three entrances can be connected into the different fluid or closed, which can be powered by pumps or high pressure pipelines. According to customer's production needs, mixing device entry can add additional flow control device. It is shown in Fig.6 that the three imported butterfly valves and three meters can be connected according to the density and flow rate required to adjust the inlet fluid flow at any time which can realize the timely adjustment and the control of density. In addition to the mixer of other devices can be temporary connected assembly, multipurpose fluid fast hybrid control device can be used in a hose connection anywhere in the factory. The above advantages make the installation and mobile operation of the product be completed by only two operators who only need training of two weeks because of its simple operation.

\section{THE TECHNOLOGY INNOVATIONS AND ADVANTAGES OF THE NEW DEVICE}

\section{A. The innovation of technology}

The technology innovations of the new device mainly includes:

1) Set up three fluid jet pipe entrance, entrance jet tube set with jet element to enhance the mixing effect;

2) The main hybrid cavity increase to slow the velocity of flow and extend the mixing time;

3) In order to enhance the mixing effect further, export mix section has a symmetrical baffle structure is installed inside.

Compared to the conventional drilling fluid mixing device, the new type of drilling fluid mixing device has the advantages of perfect mixing effect, portable easily to install and tear down, long life of using and lower economic cost[16-21].

\section{B. The advantages of device}

Existing fluid density regulating device are needed for large capacity storage containers and mixing equipment, the equipment is large, more moving equipment and parts, easy to damage, The China National Offshore Oil Corporation has launched "863" scientific research project "the surface of deep water key technology of drilling and the research of equipment" , including our school took on corpus the research of "the density of mud dynamic adjusting device "[1]. 
The equipment control accuracy is high, the mud mixing effect is wonderful, but large, complex process, the cost is too high, isn't conducive to plant the popularization and application. Can't satisfy the similar offshore drilling fluid mixed preparation in the process of rapid, stable, high reliability and space requirements.

New type of drilling fluid mixing device has the following advantages compared with the conventional drilling fluid mixing device:

1) Mixing effect is perfect

New drilling fluid mixing device using the fluid mechanics principle, through reasonable design of mixing chamber, the structure of the baffle and port, etc. effectively improve the fluid mixing effect.

2) Portable, easy to install and tear down

Compared with conventional drilling fluid mixing device the device is more light, concise, saves the space greatly, the operation of installation, dismantlement, mobile and only 2 people can finish, save manpower and material resources, production expenses increased greatly.

3) Long life

The service life of the ordinary mixing device for 2 years or so commonly, but the new type of drilling fluid mixed quickly adjusting device can be timely replacement parts necessary because of it's convenient and easy to remove to realize the extension of product life.

4) Saving economic cost

The device can be realized fast mixing and density adjustment of the drilling fluid without configuration, artificial mixing and don't need to set the moving parts. Saving the cost of artificial and power, increasing the yield of the product.

\section{CONCLUSIONS}

The multipurpose fluid mixing device can overcome the shortcomings of traditional device or microcomputer control device for mixing. Through the production test, pilot test and industrial test, it obtains good effect and achieves the expected design purpose. This device has the fluid mixing section and no movement components, which can be realized without additional energy consumption characteristics during the fluid fast mixing. The fluid density can be timely adjusted and strong operated. It is small and easy to maintain, so it can be widely used in oil, chemical, pharmaceutical, beverage, brewing and other industries, especially in the sea when drilling fluid mixed preparation which meets the requirements of effective quickly, stability, high reliability and space.

\section{REFERENCES}

[1] Kong Songtao,Lei Zongming,"The research of drilling fluid mixing mechanism, petroleum machinery",Vol.38,No.11,2010

[2] Liu Yan,Yu Xuyang,"The research of drilling fluid mixing,petroleum machinery", Vol.41,No.1,2013

[3] J. Hermoso;F. Martinez-Boza;C. Gallegos," Applied Clay Science", Vol.87,pp14-21, 2014.

[4] .Hermoso, J.;Jofore, B. D.;Martínez-Boza, F. J.;Gallegos, C.' Industrial \& Engineering Chemistry Research", Vol.51,No.44, pp14399-14407.

[5] Griffin, Jeff," Underground Construction", Vol.56, No.6,pp58, 2001.

[6] Zhu, Z.;Li, J.;Xie, S.;Yuan, G.” Petroleum Science and Technology, Vol.29, No.14, pp1470-1481, 2011.

[7] David C. Thomas;James F. Lea Jr.;E.A. Turek," Journal of Petroleum Technology", Vol.36, No.6,pp959-968, 1984.

[8] Paul, Don;Mercer, Robert," Offshore", Vol.58, No.8,pp64, 1999.

[9] Andreas Hartmann, Renate Pechnig and Christoph Clauser," International Journal of Earth Sciences”, Vol.97, NO.2,pp421-433, 2008 .

[10] Griffin, Jeff, "Underground Construction", Vol.56, No.9,pp56, 2001.

[11] Leonard-Barton, Dorothy;Sviokla, John J," Harvard Business Review", Vol.66, No.2,pp91-98, 1988.

[12] M.M. Dardir;S. Ibrahime;M. Soliman;S.D. Desouky;A.A. Hafiz,' Egyptian Journal of Petroleum”, Vol.23, No.1,pp35-43, 2014.

[13] Oil, Gas \& Petrochem Equipment Group," Oil, Gas \& Petrochem Equipment", Vol.54, No.6, 2008.

[14] Anonymous," National Driller", Vol.32, No.1,pp56-57, 2011.

[15] Steinsvag, Kjersti;Galea, Karen S.;Kruger, Kirsti;Peikli, Vegard;Sanchez-Jimenez, Araceli;Saetvedt, Esther;Searl, Alison;Cherrie, John W.;van Tongeren, Martie," Annals of Occupational Hygiene", Vol.55, No.4,pp347-356, 2011.

[16] Blanc, Leonard," Offshore”, Vol.56, No.3,pp20, 1996.

[17] Griffin, Jeff," Underground Construction", Vol.56, No.12,pp46, 2001.

[18] Pipeline and Utilities Construction”, Vol.51, No.9,pp66, 1996.

[19] Yigit, Ahmet S.;Christoforou, Andreas P," Journal of Energy Resources Technology”, Vol.128, No.4,pp268-274, 2006.

[20] Lea, James F.;Winkler, Herald W.;Snyder, Robert E.Oyewole, Peter O," World Oil", Vol.229, No.5,pp9, 2008.

[21] Chen Qingyao, Wang Jiangli,'The equipment and use of automatic drilling fluid mixing, petroleum machinery”,Vol.28,No.4,1999 